\title{
Growth Rate Differences of Chrysomya sp. Larvae on Rattus novergicus Wistar Strain Corpse Exposed and Unexposed to Ephedrine Toxic Dose
}

\author{
Sri Poeranto ${ }^{1}$, Wening Prastowo ${ }^{2}$, Diandra Laksmita Resmi ${ }^{3}$, Rivo Yudhinata Brian Nugraha ${ }^{1 *}$ \\ ${ }^{1}$ Laboratory of Parasitology, Faculty of Medicine, Brawijaya University, Malang, Indonesia \\ ${ }^{2}$ Department of Forensic, Saiful Anwar Public Hospital, Malang, Indonesia \\ ${ }^{3}$ Faculty of Medicine, Brawijaya University, Malang, Indonesia
}

\section{ABSTRACT}

Post Mortem Interval (PMI) is used as a parameter to define the onset, cause, manner, and time of death to help maintenance of law and identify crime victims by the age of the larvae found. Larval growth is influenced by the temperature, humidity, and contaminant (drug or toxic). This experiment used two media of dead rats (200 grams), one given ephedrine of $\mathrm{LD}_{50}=266 \mathrm{mg} / \mathrm{kg}$ and the other without ephedrine. Both were put in 2 cages each containing 50 Chrysomya sp. Ten larvae were randomly taken every day for 14 days to be measured their length, weight, and duration of growth. The $3^{\text {rd }}$ larvae stage in the media with ephedrine had weight gain on 5 th $-6^{\text {th }}$ day morning, while larvae in media without ephedrine had static weight gain on $5^{\text {th }}$ day morning - afternoon and weight decrement on $6-7^{\text {th }}$ day morning. Larva's peak ratio of length/weight in the media with ephedrine was higher than that of larvae in the media without ephedrine. Larvae on media with ephedrine grew faster in $1^{\text {st }}, 2^{\text {nd }}, 3^{\text {rd }}$ larvae stage, and pupal stage compared to larvae without ephedrine. Therefore, this study indicates that ephedrine can accelerate the growth rate of Chrysomya sp. larvae.

Keywords: Chrysomya sp., Ephedrine, Larval Growth

\section{INTRODUCTION}

The FDA has reported a lot of ephedrine intoxication cases, leading FDA to withdraw ephedrine supplements in 2000. However, ephedrine is still sold freely and readily available at pharmacies due to its indications that are still needed [1]. Ephedrine can help relax the bronchial muscles so that it can be used in the treatment of bronchial asthma. Ephedrine is also able to boost appetite and also methamphetamine precursor materials due its similar structure $[2,3]$.

Death according to Indonesian government regulation no. 18/1981 Article 1 paragraph 9 is the cessation of heart function, breathing, or function of the brain that is declared by medical experts authorized. Meanwhile, according to declaration of Indonesian Doctor Association no: 231 / PB / A.4 / 07/1990 point 4, death is the cessation of spontaneous breathing and heart function

\footnotetext{
*Corresponding author:

Rivo Yudhinata Brian Nugraha

Laboratory of Parasitology, Faculty of Medicine, Brawijaya

University

Jalan Veteran, Malang, Indonesia 65145

E-mail: rivo.yudhinata@gmail.com
}

which are irreversible with any evidence of brain stem death. Death can occur through a natural and unnatural process. Some examples of unnatural cause of death are homicide, accident, suicide, poisoning, and drug addiction. The incidence of deaths which are caused by the unnatural things is still a lot, still growing and increasingly worrying [4]. One branch of medicine that helps uncover cases of unnatural death is forensic entomology.

Forensic entomology is an applied science that is a combination of two fields of science, forensic and entomology. Entomology is the study of insects while forensics is the application of science to address crime and law enforcement. Thus, forensic entomology can be defined as the study of insects for the purposes of handling the problems of crime, particularly involving corpses. The most important application of forensic entomology is the approximation of Post Mortem Interval (PMI) or

\section{How to cite:}

Poeranto S, Prastowo W, Resmi DL, Nugraha RYB (2017)

Growth Rate Differences of Chrysomya sp. Larvae on Rattus novergicus Wistar Strain Corpse Exposed and Unexposed to Ephedrine Toxic Dose. J. Trop. Life. Science 7 (3): 218 - 223. 
the time of death by looking at the minimum period of insect activity on the corpses [5].

Flies play an important role in medico legal forensic entomology through their breeding. In forensic entomology, the proper identification of specimens that relate to various types of insects, especially Chrysomya sp. (egg, larva, pupa, and adult form) that were found on the bodies, is very important on post mortem interval identification. Chrysomya sp. is often discovered because this species usually comes first on a dead animal or human [5].

This study is aimed to determine the speed of larval growth in media of Rattus novergicus Wistar strain that were exposed to toxic doses of ephedrine. $R$. novergicus Wistar strain is used because it has similar metabolic physiology to human.

\section{MATERIALS AND METHODS}

\section{Research design}

This study was a laboratory experimental research with true experimental design that aimed to compare length, weight, and growth rate differences of Chrysomya sp. larva on growth media containing rat corpse with ephedrine and without ephedrine. This research was conducted at the Laboratory of Parasitology, Faculty of Medicine, Brawijaya University in November 2014.

\section{Growth Media}

In this study, rats that were used as a growth media weighted 200 grams. One cage was filled with dead rat which was previously administrated with $120 \mathrm{mg}\left(\mathrm{LD}_{50}\right.$ $=600 \mathrm{mg} / \mathrm{kg}$ ) of ephedrine orally then was euthanized by cervical dislocation after the onset of toxicity such as hyperkinesia acquired. Another cage was filled with dead rat which was euthanized by cervical dislocation without any treatment. Incision was made in the ventral midline from neck until anus so that visceral organ of rat could be clearly exposed. Then, these two cages were placed in a room with $25-28^{\circ} \mathrm{C}$ temperature.

\section{Research samples}

Chrysomya sp. was cultured in dead rat media with and without ephedrine. Fifty Chrysomya sp flies supplied by Laboratory of Parasitlogy, Brawijaya University, were put in each cage. Ten largest Chrysomya sp. larvae were selected from media with and without ephedrine which then were measured for their length, weight, and growth rate as sample.

\section{Growth rate examination}

In general, the growth of eggs into 1st larva stage larvae took $6-12$ hours, $2^{\text {nd }}$ larva stage after a day later, and $3^{\text {rd }}$ larva stage after one week. 3rd larva stage when becoming pupae would almost stop eating and moving from their host to look for a dry place. Pupae to become adult flies took $4-5$ days. Growth rate was examined every day at around $07.00-09.00$ (a) and $15.00-17.00$ (b). Ten largest larvae previously taken were inserted into hot water until death and measured for their length and weight. Larva stage was classified by observing the shape of spiracles [6].

\section{RESULTS AND DISCUSSION}

The difference in length and weight of Chrysomya sp. larvae is presented in Figure 1. The length of larvae in media without ephedrine exposure had average peak length of $17.634 \mathrm{~mm}$ when on $3^{\text {rd }}$ larva stage (day 5b) and later became pupae with an average length of 8.648 $\mathrm{mm}$. In comparison, larvae in media with ephedrine was able to reach average peak length of $17.122 \mathrm{~mm}$ when on $3^{\text {rd }}$ larva stage (day 6a) and pupae reached an average length of $9.164 \mathrm{~mm}$.

On day $3 b$, lengths of larvae that grew in media without ephedrine were almost equal to the length of larvae in media with ephedrine, that were $6.266 \mathrm{~mm}$ and $6.846 \mathrm{~mm}$ ( $p=0.050)$. As the days before, there was no significant length difference in both media on day 4 a to $5 \mathrm{a}(\mathrm{p}>0.05)$. On day 5b, larvae in media without ephedrine gained an average length of $17.634 \mathrm{~mm}$ higher than that of larvae that grew in media with ephedrine, which was $15.650 \mathrm{~mm}(p=0.003)$. Observation on day 6 a also showed a significant difference $(\mathrm{p}=0.001)$. However, the average length of larvae that grew in media containing ephedrine was $17.122 \mathrm{~mm}$ higher than that of larvae in media without Ephedrine, which was $14.840 \mathrm{~mm}$.

On day 6 b, results showed no statistically significant difference $(p=0.073)$. On day $7 a$, larvae that grew in media containing ephedrine had been transformed into pupae. Meanwhile, the larvae that grew in media without ephedrine were still in $3^{\text {rd }}$ larva stage. On day $7 \mathrm{~b}$ to 13a average length was constant where the larvae had turned into pupae. The average maximum length of pupae that grew in media with ephedrine was $9.164 \mathrm{~mm}$. Meanwhile, pupae that grew in media without ephedrine was $8.648 \mathrm{~mm}(\mathrm{p}=0.355)$.

Figure 2 showed that the growth of larvae in media containing ephedrine was able to achieve an average peak weight during $3^{\text {rd }}$ larva stage (day 5 b) with 77.12 


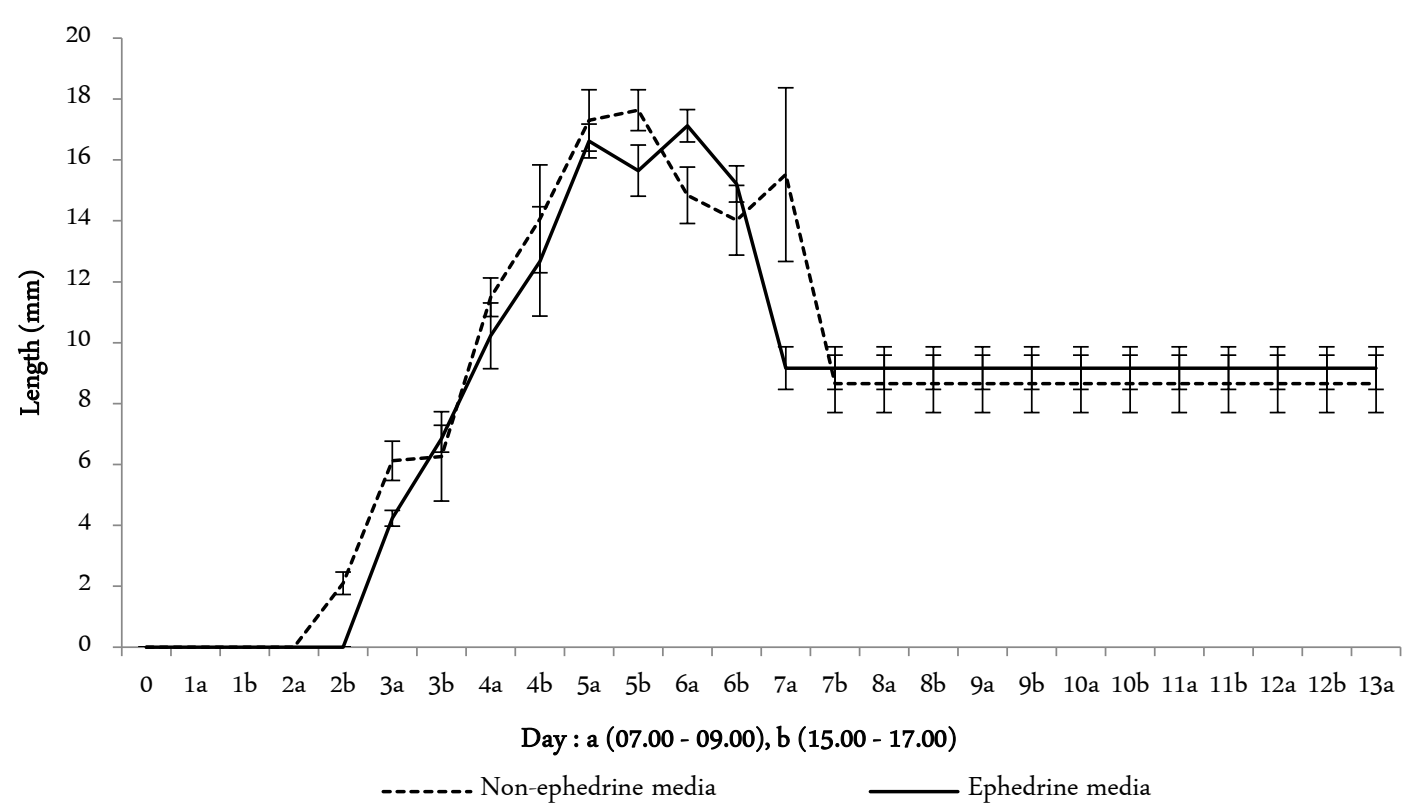

Figure 1. Comparison of Chrysomya sp. larval length on ephedrine and non-ephedrine media

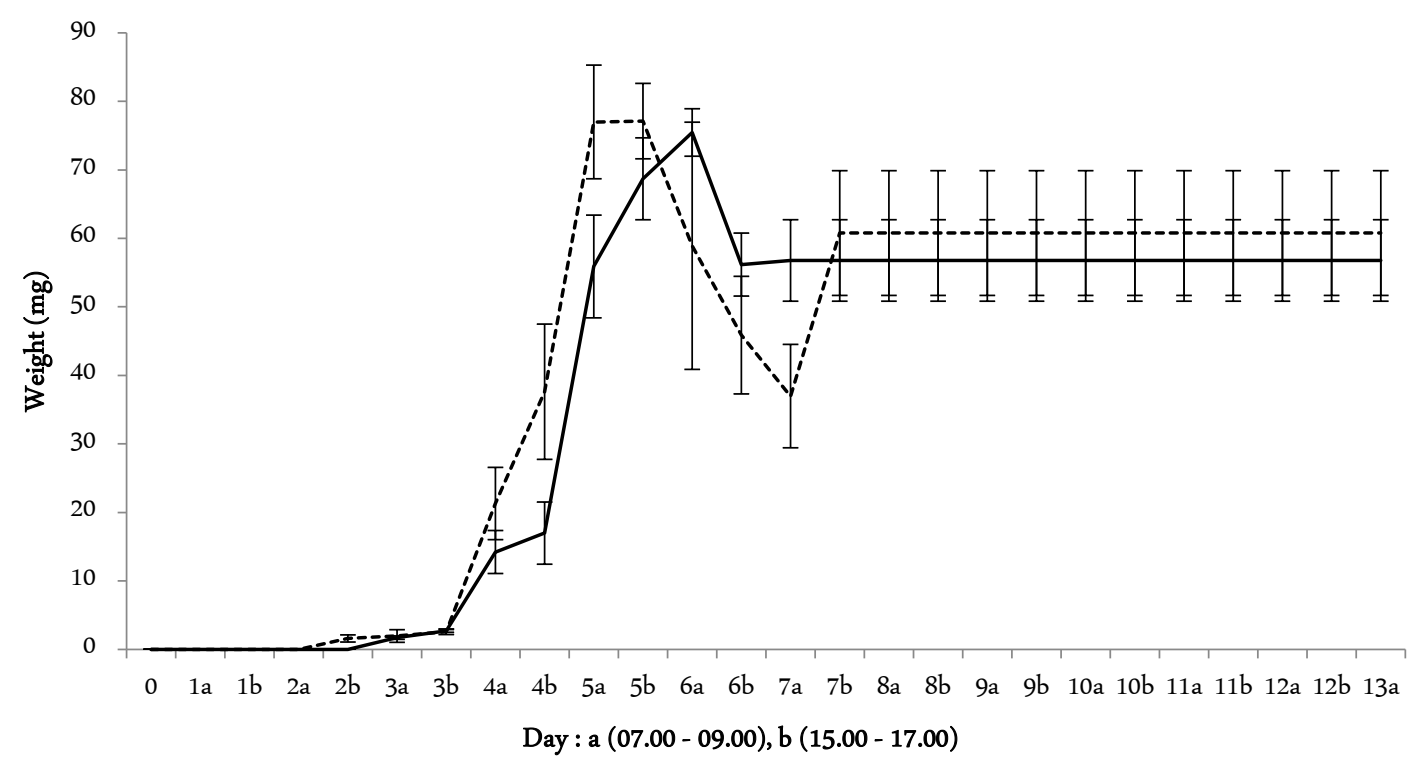

--o-- Non-ephedrine media _— Ephedrine media

Figure 2. Comparison of Chrysomya sp. larval weight on ephedrine and non-ephedrine media

mg of weight, while the larvae in media without ephedrine could reach the peak during 3rd larva stage (day 6a) with $75.46 \mathrm{mg}$ of weight. On day $4 \mathrm{a}$, the average weight of larvae in the media without ephedrine was $21.300 \mathrm{mg}$, which was higher than larvae in the media containing ephedrine with $14.220 \mathrm{mg}$ of weight $(\mathrm{p}=0.033)$.

On day $4 \mathrm{~b}$, larvae in media without ephedrine had an average weight of $37.620 \mathrm{mg}$ which was higher than that of larvae in media containing ephedrine with 16.980 $\mathrm{mg}$ of weight $(\mathrm{p}=0.003)$. This was because on day $4 \mathrm{~b}$ larvae in the media with ephedrine had been transformed into $3^{\text {rd }}$ larva stage. Day $5 \mathrm{a}$ and $5 \mathrm{~b}$ showed the average weight of larvae in media without ephedrine was higher than that of larvae on the media with ephedrine $(\mathrm{p}<0.05)$. However, on day $6 \mathrm{a}$, there was no average weight differences of larvae in both media $(p=0.079)$. While on the day $6 \mathrm{~b}$, average weight of larvae in media containing ephedrine was statistically higher than those without $(p=0.046)$. On day 7 a there was also a significant difference in weight $(p=0.002)$, but the larvae in 
media with ephedrine had been transformed into pupae. Larvae in media with ephedrine still gained more weight on day $5 a-6 a$. Meanwhile, larvae in media without ephedrine had static weight gain on day $5 a-5 b$ and subsequent larval weight reduction on day $6 a-7 a$. On day $8 \mathrm{a}$ to 13a, average weight obtained was constant because larvae had become pupae and not growing anymore. The maximum average weight of pupae in media with ephedrine was $56.780 \mathrm{mg}$ while in media without ephedrine is $60.780 \mathrm{mg}(\mathrm{p}=0.435)$.

Based on data from Figure 1 and 2, it can be concluded that the growth of larvae in media containing ephedrine undergo elongation at the egg stage and acceleration on the $1^{\text {st }}, 2^{\text {nd }}, 3^{\text {rd }}$ larva stage, and pupa stage. $1^{\text {st }}$ and $2^{\text {nd }}$ larva stage had 12 hours growth acceleration than normal. Larval growth in media containing ephedrine began after 2 days ( 48 hours), whereas larvae in media without ephedrine began after 1.5 days (36 hours). 1st larva stage's growth rate in media containing ephedrine lasted one day, while in media without ephedrine lasted 1.5 days. Growth rate of $2^{\text {nd }}$ larva stage in media containing ephedrine lasted only 12 hours, while that in media without ephedrine lasted one day. In other words, the growth of $2^{\text {nd }}$ larva stage accelerated for 12 hours. The total duration of the larval growth from $1^{\text {st }}$ to $3^{\text {rd }}$ larva stage in media containing ephedrine was 4 days, while in media without ephedrine was 5 days. These results indicated the existence of differences in duration of larval growth in media with and without ephedrine.

The growth of fly larvae is influenced by various factors, including: temperature, environment, heat generated by larvae movement, food source, contaminants, and toxins [7]. Time of death can be approximated by calculating age of insects discovered in the animal's or human's dead body which is commonly called the Post Mortem Interval (PMI) [8]. One contaminant that can affect the growth of larvae is ephedrine. This study used ephedrine toxic dose given to $R$. novergicus Wistar strain orally to determine its effect on growth and development of Chrysomya sp. larvae. Growth and development of larvae were measured for the larval length, weight, and life cycle or duration.

Ephedrine has sympathomimetic action as $\alpha$ and $\beta$ receptor agonist and also increases the release of norepinephrine from sympathetic neurons [9]. Because of increasing activity of sympathetic nervous system, this may affect larvae staging and disrupt fly's metamorphosis metabolism hormone. Ephedrine which increases the release of adrenergic nature, such as dopamine, can affect 20-hydroxyecdysone (20E) hormone contained in insect body. This hormone is an ecdysone active metabolite hormone that plays an important role in the coordination of developmental transitions, such as larval molting and metamorphosis [10, 11]. In human, hypothalamus signal which represents emotion, stress, and trauma, all can affect hypothalamus control toward growth hormone secretion. Furthermore, experiment has revealed that catecholamine, dopamine, and serotonin, all of which are released by various nervous systems within hypothalamus, can increase growth hormone secretion rate [12].

In this study, ephedrine in media influences larval growth and development process at each stage. Figure 1 shows comparison of overall average length of Chrysomya sp. larvae. On day 2 afternoon, media without ephedrine had 1st larva stage, whereas media containing ephedrine did not have any larvae, so that $\mathrm{T}$ test could not be performed. This was possibly due to starting time delay for flies to place their eggs in media containing ephedrine. On day 3 morning, average length of larvae in media without ephedrine was higher than media containing ephedrine $(p=0.000)$. On day $5 b$ larvae in media without ephedrine had higher average length than larvae grown in media containing ephedrine $(\mathrm{p}=$ 0.003 ) did. However, on day 6 morning, the average length of larvae in media containing ephedrine was higher than that of larvae in media without ephedrine $(p=0.001)$. This is because ephedrine affects Chrysomya's ecdysone hormone. On $7^{\text {th }}$ day morning, larval length showed a statistically significant difference $(p=0.001)$ because larvae in media with ephedrine had turned into pupae.

Figure 2 shows a comparison of overall average weight of Chrysomya sp. larvae. On day 3, $1^{\text {st }}$ larva stage there was no a statistically significant difference ( $p$ > 0.05 ) in each media. On day 4 , average weight of larvae in media without ephedrine was higher than that of larvae in the media with ephedrine $(\mathrm{p}=0.033)$. On day 5 , average weight of larvae in media without ephedrine was higher than that of larvae in media with ephedrine $(\mathrm{p}<$ 0.05). Further, on day 6 afternoons, average weights of larvae in media containing ephedrine was significantly higher than in media without ephedrine.

Observations of larvae were conducted starting from the length of larvae. It was found that on the first day, there were some larval length differences. This was because the newly hatched 1st larva stage did not digest dead rat. The $1^{\text {st }}$ larvae stage is still too small and their mouth are not strong enough to pierce tissue [13]. The maximum length of larva was obtained when the larva 
had entered the $3^{\text {rd }}$ larva stage or the post feeding stage, which after this stage, larvae would metamorphose into pupae. The body length of larva would decline when it entered the pupa stage. This is the underlying reason why the length of larvae can be used as a growth rate parameter until the pupa stage [13].

The first stage of feeding is commonly called as $1^{\text {st }}$ larva stage. A molting process indicates 2 nd larva stage transformation, the second phase of feeding. At this stage, the larvae eat more than $1^{\text {st }}$ larva stage. The outer skin of larvae then inflate until molting process occurs for second time to turn the larvae into $3^{\text {rd }}$ larva stage [3]. In $3^{\text {rd }}$ larva stage, there are two stages, namely feeding stage and post-feeding stage. Feeding stage larvae is the last stage of feeding. At this last stage, larvae eat greedily and have body size increment. When going into the pupa stage, $3^{\text {rd }}$ larva stage larvae will stop eating and get away from the food source to change into pupae namely Post Feeding stage. In this study, larvae in media containing ephedrine stayed away from the food source (dead rat). Later, $3^{\text {rd }}$ larva stage will turn into pupae. This process is influenced by hormones that play a role in metamorphosis. This process changes soft and yellowish white larval skin becomes blackish brown hard skin. Morphological and physiological changes occur, such as a decrease in movement, longitudinal muscle contraction, outer skin or cuticle shrinking, and cuticle color darkening.

This study showed a difference between Chrysomya sp. larvae which were exposed and unexposed by toxic doses of ephedrine. 1st larvae stage which were normally have 36 hours life cycle was found to be 24 hours. The $2^{\text {nd }}$ larvae stage was 24 -hour became 12 hours, and 3rd larvae stage were 12 hours earlier than larvae which were unexposed by ephedrine. In both media, pupal stage took 156 hours until it turns into fly, but in media containing ephedrine it took 12 hours earlier. It is because the life cycle of larvae can be altered by the presence of contaminants that affect growth hormone. In addition to larval examination, forensic toxicology tests are required to determine any contaminants that exist in bodies that may affect the growth of larvae so there is no error in determining Post Mortem Interval (PMI).

This study shows that ephedrine affects the weight of larvae, in the sense that the media containing ephedrine has larvae which are heavier than larvae breed in the media without ephedrine. On day 6 morning average weight of larvae in media with ephedrine was heavier than those in the media without ephedrine. Peak of larval length per weight ratio in the media with ephed- rine was achieved on day 6 morning with length/weight $=17.12 / 75.46=0.226875$. This ratio was higher than the peak in media without ephedrine, that was 17.364/77.12 $=0.225155$. The possible cause of this event is the aggressiveness of larvae to feed which increases, causing stratum muscularium of larvae increase in media with ephedrine exposure. A change in nutrition is one factor which influences the growth of larvae.

Life expectation of larvae can be measured by determining the larval stage. The size and length of larvae cannot be used as reference age of larvae due to the overlapping of different sizes on stage, especially 2 nd and 3rd larva stage. In addition, post-feeding stage larvae have decreased body weight and length and then turn into pupae. Staging is determined through the observation of slit on larval posterior spiracles. Larvae undergo molting twice at $1^{\text {st }}$ to $2^{\text {nd }}$ larva stage and from $2^{\text {nd }}$ to $3^{\text {rd }}$ larva stage. Then, the larvae will undergo pupariation into pupae until later become adult flies [13]. To see the effect of ephedrine in detail at every stage, the examination of the posterior spiracles is performed. On day 5 afternoon, larvae in media without ephedrine still have 2 pieces of slit on posterior spiracles while larvae in media containing ephedrine already have 3 pieces of slit on posterior spiracles.

Some difficulties were encountered in this study. The number of samples used was 10 larvae per day. Multiplying the number of samples might cause a shortage of samples for subsequent observations because of difficulty to ensure the number of flies that laid eggs in the media. This study did not specifically look at the difference of larval growth in organs with high drug distribution.

\section{CONCLUSION}

It can be concluded that there are significant differences in the length of the Chrysomya sp. larvae. exposed to ephedrine toxic doses compared with the unexposed ones; there are significant differences in larval weight between larvae exposed to toxic doses ephedrine compared to unexposed ones; and ephedrine accelerates growth rate of Chrysomya sp. at $2^{\text {nd }}$ to $3^{\text {rd }}$ larvae stage for 12 hours, $3^{\text {rd }}$ larvae stage to pupae for 12 hours, and transformation from pupae to adult flies for 12 hours.

\section{ACKNOWLEDGMENT}

The researchers would like to thank the Faculty of Medicine, Brawijaya University for facilitating this research. 


\section{REFERENCES}

1. Haller CA, Duan M, Benowitz NL, Jacob P (2004) Concentrations of ephedra alkaloids and caffeine in commercial dietary supplements. Journal of Analytical Toxicology 28 (3): $145-151$.

2. Brunton LL (2011) Goodman and Gilman's the pharmacological basis of therapeutics. New York, McGraw-Hill Medical.

3. Lee MR (2011) The history of Ephedra (ma-huang). The journal of the Royal College of Physicians of Edinburgh 41 (1): 78 - 84. doi: 10.4997/JRCPE.2011.116.

4. Gill GJ (2005) Decomposition and arthropod succession on above ground pig carrion in Rural Manitoba. Master Thesis. Department of Entomology, University of Manitoba.

5. Byrd JH, Castner JL (2012) Forensic Entomology: The Utility of Arthropods in Legal Investigations, $2^{\text {nd }}$ ed. Boca Raton, FL, CRC Press.

6. The World Organisation for Animal Health (OIE) (2008). OIE terrestrial manual 2008: New World Screwworm (Cochliomyia hominivorax) and Old World Screwworm (Chrysomya bezziana). https://web.oie.int/, Accessed: August 2017.

7. Sribanditmongkol P, Monum T, Wannasan A et al. (2014) Blow fly maggots (Diptera: Calliphoridae) from a human corpse in a vehicle. The Southeast Asian Journal of Tropical Medicine and Public Health 45 (5): 1011-1014.

8. Zehner R, Mosch S, Amendt J (2006) Estimating the postmortem interval by determining the age of fly pupae: Are there any molecular tools?. International Congress Series 1288: 619-621. doi: 10.1016/j.ics.2005.12.007

9. Karch SB, Drummer O (2008) Karch's Pathology of Drug Abuse, $4^{\text {th }}$ ed. Boca Raton, FL, CRC Press.

10. Hiruma K, Kaneko Y (2013) Hormonal regulation of insect metamorphosis with special reference to juvenile hormone biosynthesis. Current Topics in Developmental Biology: 103 73 - 100. doi: 10.1016/B978-0-12-385979-2.00003-4.

11. Ishimoto H, Sakai T, Kitamoto T (2009) Ecdysone signaling regulates the formation of long-term courtship memory in adult Drosophila melanogaster. Proceedings of the National Academy of Sciences of the United States of America 106 (15): 6381 - 6386. doi: 10.1073/pnas.0810213106.

12. Guyton AC, Hall JE (2008) Textbook of medical physiology, $11^{\text {th }}$ ed. Jakarta, EGC Medical Publisher.

13. Duke LD (2004) Effects of amitriptyline and nortriptyline on time of death estimations in the later postmortem interval using insect development. Ottawa, Canadian Police Research Centre (CPRC). 